\title{
Range limitation of the Peaks of Otter salamander (Plethodon hubrichti) due to competition with the eastern red-backed salamander (Plethodon cinereus) in sympatry
}

\author{
TIMOTHY R. BROPHY* \& NORMAN REICHENBACH \\ Department of Biology and Chemistry, Liberty University, Lynchburg, VA 24515, USA \\ ${ }^{*}$ Corresponding author e-mail: tbrophy@liberty.edu
}

\begin{abstract}
The Peaks of Otter salamander, Plethodon hubrichti, is a montane species found at altitudes above $442 \mathrm{~m}$ within a $117 \mathrm{~km}^{2}$ area of the Blue Ridge Mountains in central Virginia, USA. In areas where this species is sympatric with the eastern red-backed salamander (Plethodon cinereus) it seemed likely that $P$. hubrichti populations were either depressed or eliminated. The habitability of areas beyond the current range boundaries for $P$. hubrichti is supported by several disjunct populations in areas sympatric with $P$. cinereus. From 2009 to 2012 we tested whether $P$. hubrichti was negatively impacted by competition with $P$. cinereus by removing $P$. cinereus from treatment plots at three sympatric field locations. The number of surface-active (SA) $P$. hubrichti increased significantly more on treatment plots than on corresponding reference plots, whereas the number of SA $P$. cinereus decreased significantly more on treatment plots than on reference plots. The removal of every one $P$. cinereus from the treatment plots led to an increase of 0.69 P. hubrichti. These results emphasise the importance of conserving mature hardwood forests along the perimeter of the $P$. hubrichti distribution, where it is sympatric with $P$. cinereus, so as to prevent future range contraction of this vulnerable species.
\end{abstract}

\section{INTRODUCTION}

$\mathrm{T}^{\mathrm{h}}$ he Peaks of Otter salamander (Plethodon hubrichti) is one of several endemic salamander species found in the state of Virginia, USA (Kramer et al., 1993; Petranka, 1998). It is a montane species with a very limited distribution, being found only in mature, deciduous forests at altitudes greater than $442 \mathrm{~m}$ within a $117 \mathrm{~km}^{2}$ area of the Blue Ridge Mountains in central Virginia (Pague \& Mitchell, 1990). We demonstrated previously that declines in altitude, which are associated with rises in temperature and falls in relative humidity, depressed the densities, survival rates, growth rates, eggs per female, and reproductive output of surfaceactive $P$. hubrichti (Reichenbach \& Brophy, 2017). We also showed that $P$. hubrichti had greater dehydration rates and lower critical thermal maxima than the wider-ranging eastern red-backed salamander (Plethodon cinereus), reflecting its adaptation to montane environments (Reichenbach \& Brophy, 2017). Based on these findings, we hypothesised that at low altitudes where $P$. cinereus, a potential competitor, is absent the range of $P$. hubrichti is limited primarily by abiotic factors; Arif et al. (2007) consider the entire distribution of $P$. hubrichti to be limited primarily by abiotic factors.

Interspecific competition is extremely common among salamanders in the genus Plethodon (Adams, 2007; Anthony et al., 1997; Hairston, 1980a, b; Jaeger, 1971, 1974; Marshall et al., 2004) and has frequently been cited as a limiting factor in the distribution of some of its species (Jaeger, 1970, 1971, 1980; Hairston, 1980b; Griffis \& Jaeger, 1998). Plethodon cinereus, a wide-ranging and tolerant species (Petranka, 1998; Adams, 2007), has been implicated in limiting the distributions of several Virginia/West Virginia montane salamander endemics through interspecific competition (Highton, 1972; Jaeger, 1970, 1974; Pauley, 1991, 2005; Wicknick, 1995; Jaeger et al., 2002; Griffis \& Jaeger, 1998; Kroschel, et al., 2014; Farallo \& Miles, 2016). In fact, Wicknick (1995) found that $P$. cinereus and $P$. hubrichti showed evidence of interspecific competition with no clearly superior competitor, which led Jaeger et al. (2002) to suggest that their contact zone is static and, by inference, that competition is limiting the distribution of both species. A definitive way to demonstrate interspecific competition is by selective removal; for example Hairston (1980b) found that removal of the competitive species, $P$. jordani, led to significant increases in the number of $P$. teyahalee (formerly $P$. glutinosus) on experimental plots in North Carolina and Tennessee, USA.

There are many locations within the Peaks of Otter area of central Virginia where $P$. hubrichti is not found. Many of these locations, especially those NE and SW of its current species' distribution, have suitable habitat and are found at altitudes optimal (or near-optimal) for its survival and reproduction (Reichenbach \& Brophy, 2017; see also Fig. 5A in Arif et al., 2007). We find no reason why P. hubrichti could not occupy such locations were it not for the potentially competitive presence of $P$. cinereus. Unlike our previous hypothesis regarding abiotic limitations in low altitude areas where $P$. cinereus is absent (Reichenbach \& Brophy, 2017), we hypothesise that in areas where they are sympatric, $P$. hubrichti populations are depressed through competition with $P$. cinereus and that this competition is limiting the range of $P$. hubrichti in areas that would otherwise be habitable. To test this hypothesis experimentally we used removal studies at field locations where the two species were sympatric. 


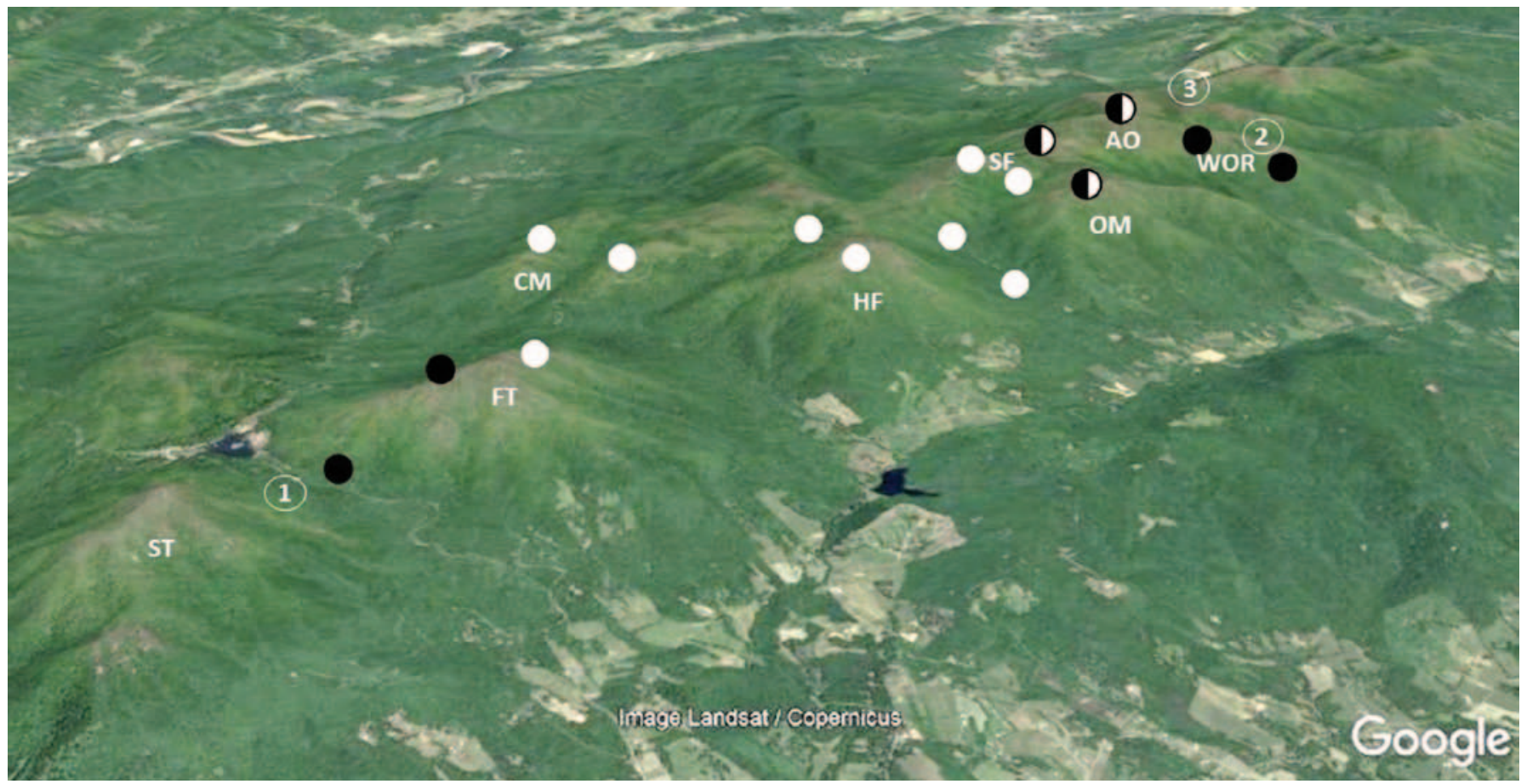

Figure 1. Peaks of Otter, Blue Ridge Mountains, VA. White dots represent allopatric Plethodon hubrichti sites, black dots are allopatric $P$. cinereus sites, and white \& black dots are sympatric sites. ST - Sharp Top Mountain, FT - Flat Top Mountain, CM - Chestnut Mountain, HF Headforemost Mountain, OM - Onion Mountain, SF - Sunset Fields, AO - Apple Orchard Mountain, WOR - White Oak Ridge; 1 - disjunct $P$. hubrichti population, Wright, 1988; 2 - disjunct P. hubrichti population, Pague \& Mitchell, 1990 and F. Huber, Reichenbach, Brophy, and P.W. Sattler, unpublished data; 3 - disjunct P. hubrichti population, Pague et al., 1992 and Reichenbach, unpublished data. Other site information from Reichenbach \& Sattler, 2007, Reichenbach \& Brophy, 2017 and Brophy \& Reichenbach, this study and unpublished data. Original image accessed on 11 September 2019 from https://www.google.com/earth.

\section{MATERIALS AND METHODS}

A pair of unfenced plots, each plot measuring $15 \times 15 \mathrm{~m}$, were selected at each of three different sites in the Peaks of Otter area (Blue Ridge Parkway National Park and George Washington National Forest) where $P$. hubrichti and $P$. cinereus were sympatric: Onion Mountain (OM), NE aspect, $1158 \mathrm{~m}$ asl; Sunset Fields (SF), SE aspect, $1189 \mathrm{~m}$ asl; and Apple Orchard Mountain (AO), N aspect, $1280 \mathrm{~m}$ asl (this site is within $8 \mathrm{~m}$ of the highest altitude in the $P$. hubrichti range, AO summit) (Fig. 1). The two plots at each site were assigned randomly to be either a reference plot (no $P$. cinereus removed) or a treatment plot ( $P$. cinereus removed after baseline year data collected), and were within approximately 15 to $30 \mathrm{~m}$ of one another. Surface-active (SA) $P$. hubrichti and $P$. cinereus were counted at all three sites on the same day, with paired reference and treatment plots being sampled simultaneously by two field teams consisting of six to ten members each. All sites were sampled several times annually from 2009 through 2012 (5x in 2009, 2x in $2010,4 x$ in 2011, and 3x in 2012).

Removal of $P$. cinereus from the treatment plots began on the last trip of 2009 (baseline year) and continued on each of the sampling dates throughout the duration of the study. Each treatment plot also had a $1.0 \mathrm{~m}$ buffer from which $P$. cinereus were removed but not counted in the total for that plot. Our decision to use unfenced plots stems from the observation in an earlier study that the two species moved in a similar way and covered only short distances; median distances (and interquartile range) moved were $0.71 \mathrm{~m}(\mathrm{IQR}=0.62, \mathrm{n}=44)$ and $1.00 \mathrm{~m}(\mathrm{IQR}=1.00, \mathrm{n}=31)$ for $P$. hubrichti and $P$. cinereus, respectively (Kniowski \& Reichenbach, 2009). There were no significant differences between linear distances moved ( $U$ $=634.0, n=75, P=0.60$ ) for the two species. These data suggest that no one species would migrate into our study plots more than the other. The three year duration of our study was based on the findings of Hairston (1980b) who detected competition after three years in a similar removal study with $P$. jordani and $P$. teyahalee (formerly $P$. glutinosus) in North Carolina and Tennessee, USA.

SA salamanders were located by carefully turning over rocks and logs and sifting through leaf litter on cool days, following rain, so that all plots were moist and cool throughout the day. In all cases, salamanders were captured and handled in such a way as to reduce stress and discomfort. Salamanders were categorised into neonate or juvenile/adult groupings based on size. Neonates were only present in the autumn collections and were, therefore, not included in SA salamander counts used to assess interspecific competition. At treatment sites, removed $P$. cinereus were placed in ziplock bags with damp paper towels and then placed in coolers. We limited the number of salamanders placed in each bag so as to avoid overcrowding. Salamanders were then transported in enclosed vehicles and released later that same day in allopatric $P$. cinereus areas located within National Park boundaries, but distant from our study sites. We were also careful to release only a few $P$. cinereus by each natural cover object in the forest (i.e. rock or log) so they were evenly distributed among resident salamanders. These methods were employed to maximise survival of released animals. The experiment involved only the removal of $P$. cinereus and not $P$. hubrichti which has a very limited distribution and is currently considered a Tier I species ('Critical Conservation Need') on the Virginia Department of Game and Inland 
Fisheries' list of "Species of Greatest Conservation Need" (Burkett, 2015). We wished to avoid favouring P. cinereus populations in any location within the range of $P$. hubrichti.

In this study, SA salamander counts were used as a proxy for population size because they correlated well with population estimates in previous mark-recapture studies, including one involving $P$. hubrichti (Smith \& Petranka, 2000; Reichenbach \& Sattler, 2007; Gifford \& Kozak, 2012). Counts of SA salamanders should also be comparable between the two species since one of us found, during a mark-recapture study conducted in 2005 (Kniowski \& Reichenbach, 2009), that detection probabilities were similar for $P$. hubrichti and $P$. cinereus, $0.309(95 \% \mathrm{Cl}=0.233-0.397)$ and $0.251(95 \% \mathrm{Cl}$ $=0.175-0.347)$, respectively. Any potential reductions in SA $P$. cinereus or increases in SA $P$. hubrichti in treatment (i.e. removal) plots would, therefore, not simply be artefacts of one species spending more/less time at the surface.

Our study design was a replicated ( 3 replicates) pre and post-treatment difference in SA salamander counts for each species and each plot during baseline (2009) and subsequent years (2010 to 2012). Mean SA salamander counts from 2009 through 2012 were used to describe changes seen over time in the treatment and reference plots. Differences in SA salamander counts pre (2009) and post-treatment (2012) were compared using two-sample t-tests (one-tailed) to examine 1) declines in SA salamander counts for $P$. cinereus and 2) increases in SA salamander counts for $P$. hubrichti. Normality (Shapiro-Wilk test) and homogeneity of variances (F-test) were confirmed for data using SPSS software (SPSS Inc., Chicago, IL, USA) or EXCEL (Microsoft Corp., Redmond, WA, USA).

\section{RESULTS}

At the end of 2009, prior to removal of $P$. cinereus from the treatment plots, two of our sites (SF and $\mathrm{AO}$ ) were generally dominated by $P$. cinereus and the other (OM) by $P$. hubrichti (Table 1). By the end of 2012, a total of 1020 P. cinereus had been removed from our three treatment plots (SF - 520, AO - 314, and OM - 186).

Table 1. Mean surface-active salamander counts for $P$. hubrichti $(P h)$ and $P$. cinereus $(P C)$ at both treatment (Trt) and reference (Ref) plots from 2009 to 2012. Pre and post-treatment differences were calculated by subtracting 2009 from 2012 values.

\begin{tabular}{|l|c|c|c|c|}
\hline & $P h$-Trt & Ph-Ref & Pc-Trt & Pc-Ref \\
\hline Sunset Fields & & & & \\
2009 & 8.8 & 7.8 & 28.8 & 38.8 \\
2010 & 9.0 & 6.5 & 24.5 & 30.5 \\
2011 & 18.8 & 12.3 & 31.3 & 49.0 \\
2012 & 14.7 & 10.3 & 21.3 & 45.0 \\
Pre \& post-treatment difference & +5.9 & +2.5 & -7.5 & +6.2 \\
\hline Apple Orchard Mountain & & & & \\
2009 & 8.2 & 12.4 & 22.0 & 10.6 \\
2010 & 8.0 & 6.5 & 13.5 & 7.5 \\
2011 & 13.8 & 7.5 & 19.8 & 8.8 \\
2012 & 22.3 & 13.0 & 17.3 & 16.3 \\
Pre \& post-treatment difference & +14.1 & +0.6 & -4.7 & +5.7 \\
\hline Onion Mountain & & & & \\
2009 & 30.2 & 37.8 & 18.4 & 27.2 \\
2010 & 31.0 & 32.0 & 14.0 & 19.5 \\
2011 & 45.8 & 43.5 & 10.3 & 29.3 \\
2012 & 43.0 & 45.0 & 10.7 & 27.7 \\
Pre \& post-treatment difference & +12.8 & +7.2 & -7.7 & +0.5 \\
\hline
\end{tabular}

Overall, the mean number of SA $P$. hubrichti increased substantially on treatment plots (i.e. following $P$. cinereus removal) and rather less on corresponding reference plots. In 2009, mean SA P. hubrichti counts ranged from 8.2-30.2 in the treatment plots but by 2012 had increased to 14.743.0 (Table 1). This resulted in pre and post-treatment differences in the number of $P$. hubrichti ranging from +5.9 to +14.1 at treatment plots during this three-year period (Table 1). By comparison, the differences in references plots were increases of +0.6 to +7.2 (Table 1 ).

The overall trends for $P$. cinereus were much different at treatment (i.e. removal) plots. In 2009, mean SA P. cinereus counts ranged from 18.4-28.8 in the treatment plots but decreased to $10.7-21.3$ by 2012 (Table 1 ). This resulted in pre and post-treatment differences of -4.7 to -7.7 during this three-year period (Table 1). On the other hand, trends for $P$. cinereus at reference plots mirrored those of their $P$. hubrichti counterparts on those same plots. In 2009, mean SA $P$. cinereus counts ranged from 10.6-38.8 in the reference plots and increased to $16.3-45.0$ by 2012 (Table 1 ) resulting in pre and post-treatment differences for $P$. cinereus ranging from +0.5 to +6.2 (Table 1 ).

The number of SA $P$. hubrichti increased significantly more on treatment plots than on corresponding reference plots ( $\mathrm{t}=2.32, d f=4, \mathrm{P}=0.04$; Fig. 2 ), whereas the number of SA $P$. cinereus decreased significantly more on treatment (i.e. removal) plots than on reference plots $(\mathrm{t}=-5.17, d f=4$, $\mathrm{P}=0.003$; Fig. 2). Averaging across treatment plots, and adjusting for corresponding changes in reference plots, $P$. cinereus declined overall by 10.8 salamanders whereas $P$. hubrichti increased by 7.5 salamanders during this three year period (Fig. 2). Or stated another way, the removal of every one $P$. cinereus from the treatment plots led to an increase of 0.69 P. hubrichti.

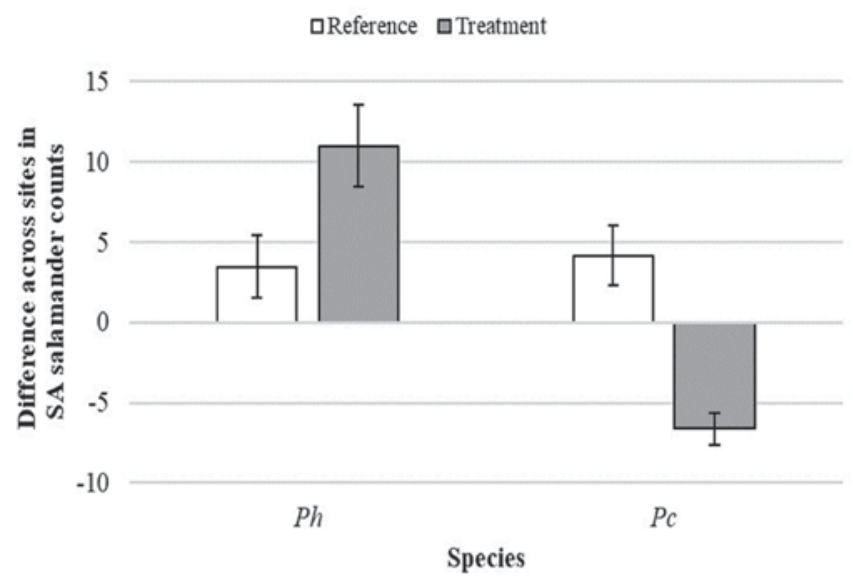

Figure 2. Pre and post-treatment differences across sites in surfaceactive (SA) salamander counts (means $\pm 1 \mathrm{SE}, \mathrm{N}=3$ ) for $P$. hubrichti $(P h)$ and $P$. cinereus $(P C)$ in both reference and treatment plots.

\section{DISCUSSION}

Plethodon hubrichti is restricted to mature hardwood forests at altitudes above $442 \mathrm{~m}$ in the Peaks of Otter area of central Virginia (Pague \& Mitchell, 1990; Reichenbach \& Brophy, 2017). Within the Peaks of Otter area, there are mature forests at altitudes well above $442 \mathrm{~m}$ that are occupied by $P$. cinereus but not $P$. hubrichti (Fig. 1). We hypothesised that, in these areas, $P$. hubrichti is restricted by 
interspecific competition with $P$. cinereus instead of abiotic factors that limit its range at lower altitudes (Reichenbach \& Brophy, 2017). The results of our removal study support this hypothesis (Table $1 ;$ Fig. 2). The rise in count of $P$. hubrichti in response to the removal of $P$. cinereus was less than the fall in count of $P$. cinereus (0.69:1). This was partially due to the fact that on average $P$. hubrichti is the larger of the two species (Kniowski \& Reichenbach, 2009; Wicknick, 1995).

There is broad niche overlap between $P$. cinereus and $P$. hubrichti which are similar in terms of diet (Petranka, 1998), microhabitat use (Kniowski \& Reichenbach, 2009), territoriality (Wicknick, 1995), foraging time and strategy (Kramer et al., 1993; Jaeger, 1978), and nesting sites (Kniowski \& Reichenbach, 2009; Petranka, 1998). Interspecific competition is well documented in plethodontid salamanders (Jaeger, 1971, 1974; Jaeger et al., 2002; Hairston, 1980a, b, 1981) and in both lab and field studies on P. hubrichti and $P$. cinereus the two species showed evidence of interspecific competition without a clearly superior competitor (Wicknick, 1995). This led Jaeger et al. (2002) to suggest that the contact zone between the two species was static which has been supported by a reexamination of Wicknick's (1995) three sites in the National Park (one allopatric P. hubrichti, one allopatric $P$. cinereus, and one sympatric site), ten years later by Aasen \& Reichenbach (2004). They showed that proportions of $P$. hubrichti relative to $P$. cinereus remained static in the undisturbed sympatric site.

Interspecific competition has long been suspected for plethodontid salamanders, but the specific effects of this type of competition are not well known. Character displacement has been noted in some interactions (Jaeger et al., 2002; Adams et al., 2007; Adams, 2010), range restrictions in other interactions (Jaeger, 1970, 1971; Hairston, 1980b), and population suppression in still others (Hairston, 1980b, 1981). For example, Jaeger (1971) determined that $P$. shenandoah would be able to survive beyond its typical talus slope locations, but was being competitively inhibited from doing so by $P$. cinereus. Additionally, Hairston (1980b) determined that a release from interspecific competition led to significant increases in $P$. teyahalee (formerly $P$. glutinosus) numbers on plots where $P$. jordani had been removed. Similarly, we demonstrate here that removing $P$. cinereus from treatment plots resulted in increased numbers of SA $P$. hubrichti (Table 1; Fig. 2). Since SA P. hubrichti counts correlate significantly with population estimates (Reichenbach \& Sattler, 2007), we infer that $P$. cinereus depresses $P$. hubrichti populations and in some locations, depending upon the size of the $P$. cinereus population, might actually prevent coexistence of the two species. These inferences are also supported by the observation, from several of our previous studies, that $P$. hubrichti densities are considerably higher when found alone $\left(1.6-3.3 / \mathrm{m}^{2}\right)$ than they are in sympatry with $P$. cinereus $\left(0.6 / \mathrm{m}^{2}\right)$ (Kramer et al., 1993; Sattler \& Reichenbach, 1998; Kniowski \& Reichenbach, 2009).

In the NE corner of the $P$. hubrichti distribution, the transition from allopatric $P$. hubrichti areas to allopatric $P$. cinereus areas occurs in less than $1 \mathrm{~km}$. This same transition, although documented for fewer sites, also occurs in the SW part of the $P$. hubrichti distribution midway on Flat Top Mountain (Fig. 1). The effects of $P$. cinereus on $P$. hubrichti, as demonstrated in this study, support the hypothesis that $P$. cinereus is competitively inhibiting $P$. hubrichti from expanding its range into areas with suitable altitudes and ecological conditions in the Peaks of Otter area, both to the NE and SW of its current range near the Blue Ridge Parkway
(Reichenbach \& Brophy, 2017; see also Fig. 5A in Arif et al., 2007).

Disjunct populations of $P$. hubrichti in the SW and NE of the Peaks of Otter area also support the hypothesis that $P$. cinereus is competitively inhibiting $P$. hubrichti from expanding its range into areas with suitable altitudes and ecological conditions. In 1987, Wright (1988) found two specimens on a steep hemlock-birch slope, $744 \mathrm{~m}$ in altitude, $2.2 \mathrm{~km} \mathrm{SW}$ from the nearest known location on the slopes of Flat Top Mountain (Fig. 1). In the NE part of the Peaks of Otter area, Pague \& Mitchell (1990) found a P. hubrichti population just NE of White Oak Ridge. We confirmed that this population still exists and that it is likely disjunct (Fig. 1). Only $P$. cinereus was found along White Oak Ridge itself, and the nearest record for $P$. hubrichti is $1.5 \mathrm{~km}$ to the $S W$ on Onion Mountain. This disjunct population ranges in altitude from 853 to $1097 \mathrm{~m}$ and is comprised, at its core, of large boulders on a steep slope. In two days of searching this area, we found 96 P. hubrichti (unpublished data; F. Huber, Reichenbach, Brophy, and P.W. Sattler). An additional disjunct population occurs even further to the NE at Thunder Ridge, $2.2 \mathrm{~km}$ from the White Oak Ridge population described above (Fig. 1). Two individuals were found at this location in 1991 (Pague et al., 1992) with six individuals discovered in October 2019 (unpublished data; Reichenbach). These disjunct populations suggest that $P$. hubrichti may have once had a wider distribution, at least along the NE/SW axis of its distribution, where altitudes are greater than $442 \mathrm{~m}$. Plethodon hubrichti populations potentially persist in these areas because steep slopes and/or boulder fields limit timbering activities. In addition, boulder fields may have provided refuges for $P$. hubrichti from the effects of clear cutting and/or forest fires; a similar explanation has been proposed for multiple disjunct populations of $P$. nettingi in West Virginia (Pauley, 2008).

We propose that overall the distribution of $P$. hubrichti is limited by two main factors. In descending from mountains, relative humidities gradually fall as temperatures rise at comparable rates. In areas where $P$. cinereus is absent, these factors eventually create physiologically intolerable conditions for $P$. hubrichti and, therefore, place abiotic restrictions on its range (Reichenbach \& Brophy, 2017; Arif et al., 2007). In areas with altitudes that are habitable by $P$. hubrichti (areas to the NE and SW of species distribution at altitudes greater than $442 \mathrm{~m}$ ), we suggest that interspecific competition with $P$. cinereus is the primary factor restricting the range of $P$. hubrichti and that, in these areas, it is not restricted abiotically.

Understanding the reasons why the Peaks of Otter salamander has such a restricted distribution can contribute greatly to its conservation. In the core of its range, where altitudes are optimal and $P$. cinereus is absent, $P$. hubrichti dominates the salamander community $(94.8 \%$ of salamander species) and can be found at high population densities (mean $=2.7 / \mathrm{m}^{2}$; Reichenbach \& Sattler, 2007). It is along the perimeter of this species' distribution, however, that extreme care must be exercised in forest management. The perimeter includes not only lower altitude areas but also areas sympatric with $P$. cinereus. These areas represent fragile salamander habitats where reduction of the forest canopy, due to timber removal or insect defoliation, would likely lead to increased temperatures and decreased relative humidities (Homyack et al., 2011). Such factors would subsequently lead to decreases in $P$. hubrichti densities in areas where it is allopatric with P. cinereus (Reichenbach \& Brophy, 2017). In areas where $P$. hubrichti is sympatric with $P$. cinereus, we 
predict that these same conditions would favour $P$. cinereus, the more widespread and, therefore, tolerant species which has virtually no altitudinal (e.g. found at highest altitudes at $\mathrm{AO}$ summit) or ecological restrictions (see Fig. 5B in Arif et al., 2007 ) within the range of $P$. hubrichti at present. Adams et al. (2007) suggested that $P$. cinereus may have morphological and behavioural flexibilities that allow it to adapt quickly to altered, local environmental conditions. This might give it a competitive advantage over $P$. hubrichti in becoming re-established in recovering forests. The net result of this situation would be to reduce the already limited distribution of $P$. hubrichti even more. Perhaps this is what occurred in areas surrounding the disjunct populations described above. Both private and public managers, such as those from the National Park and Forest services who manage the majority of land occupied by $P$. hubrichti, should focus conservation efforts on these perimeter areas so as to prevent future contraction of this vulnerable species' range.

\section{ACKNOWLEDGEMENTS}

This study was funded in part by grants from Liberty University, Liberty Alumni Research Grant Program, and Virginia Herpetological Society. Permits were obtained from the National Park Service (National Park Scientific Research and Collecting Permits BLRI-2009-0002, BLRI-2010-0002, BLRI-2011-0002, and BLRI-2012-0002), National Forest Service, and Virginia Department of Game and Inland Fisheries. This study complies with ethical guidelines, regarding the use of live amphibians in field research, as described by the British Herpetological Society (2017) and the Herpetological Animal Care and Use Committee of the American Society of Ichthyologists and Herpetologists (2004). Students from Liberty University, particularly Christina Fantasia, Amy Parker, and Kate Eaton, helped in many aspects of this research. Liam Cusack, Olivia de Araujo, Savannah Dunn, Jesse Hughes, Hannah Kinsley, Elisabeth Russell, and Hannah Suber assisted in the field work on White Oak Ridge. We are heavily indebted to all who gave up their Saturdays to help conserve this species. Early drafts of this manuscript were greatly improved by the comments of Andrew Kniowski, Renee Pietsch, and Cory Goff.

\section{REFERENCES}

Aasen, G. \& Reichenbach, N. (2004). Is the red-backed salamander encroaching upon populations of the Peaks of Otter salamander? Catesbeiana 24: 17-20.

Adams, D.C. (2007). Organization of Plethodon salamander communities: guild-based community assembly. Ecology 88: 1292-1299.

Adams, D.C. (2010). Parallel evolution of character displacement driven by competitive selection in terrestrial salamanders. BMC Evolutionary Biology 10: 1-10.

Adams, D.C., West, M.E. \& Collyer, M.L. (2007). Locationspecific sympatric morphological divergence as a possible response to species interactions in West Virginia Plethodon salamander communities. Journal of Animal Ecology 76: 289-295.

Anthony, C.D., Wicknick, J.A. \& Jaeger, R.G. (1997). Social interactions in two sympatric salamanders: effectiveness of a highly aggressive strategy. Behaviour 134: 71-88.

Arif, S., Adams, D.C. \& Wicknick, J.A. (2007). Bioclimatic modeling, morphology, and behavior reveal alternative mechanisms regulating the distributions of two parapatric salamander species. Evolutionary Ecology Research 9: 843-854.

British Herpetological Society (2017). British Herpetological Society: Ethical policy and guidelines. The Herpetological Bulletin 141: 46-48.

Burkett, T.C. (2015). Virginia's 2015 Wildlife Action Plan. Henrico, VA: Virginia Department of Game and Inland Fisheries. 1135 pp.

Farallo, V.R. \& Miles, D.B. (2016). The importance of microhabitat: a comparison of two microendemic species of Plethodon to the widespread P. cinereus. Copeia 2016: 67-77.

Gifford, M.E. \& Kozak, K.H. (2012). Islands in the sky or squeezed at the top? Ecological causes of elevational range limits in montane salamanders. Ecography 35: 193203.

Griffis, M.R. \& Jaeger, R.G. (1998). Competition leads to an extinction-prone species of salamander: interspecific territoriality in a meta-population. Ecology 79: 24942502.

HACC (2004). Guidelines for use of Live Amphibians and Reptiles in Field and Laboratory Research. Second edition. Herpetological Animal Care and Use Committee of the American Society of Ichthyologists and Herpetologists. 43 pp.

Hairston, N.G. (1980a). Evolution under interspecific competition: field experiments on terrestrial salamanders. Evolution 34: 409-420.

Hairston, N.G. (1980b). The experimental test of an analysis of field distributions: competition in terrestrial salamanders. Ecology 61: 817-826.

Hairston, N.G. (1981). An experimental test of a guild: salamander competition. Ecology 62: 65-72.

Highton, R. (1972). Distributional interactions among eastern North American salamanders of the genus Plethodon. In The Distributional History of the Biota of the Southern Appalachians Part III: Vertebrates, 139-188 pp. Holt, P.C., Paterson, R.A \& Hubbard, J.P. (Eds.). Blacksburg, VA: Virginia Polytechnic and State University.

Homyack, J.A., Haas, C.A. \& Hopkins, W.A. (2011). Energetics of surface-active terrestrial salamanders in experimentally harvested forest. The Journal of Wildlife Management 75: $1267-1278$

Jaeger, R.G. (1970). Potential extinction through competition between two species of terrestrial salamanders. Evolution 24: 632-642.

Jaeger, R.G. (1971). Competitive exclusion as a factor influencing the distributions of two species of terrestrial salamanders. Ecology 52: 632-637.

Jaeger, R.G. (1974). Competitive exclusion: comments on survival and extinction of species. Bioscience 24: 33-39.

Jaeger, R.G. (1978). Plant climbing by salamanders: periodic availability of plant-dwelling prey. Copeia 1978: 686-691.

Jaeger, R.G. (1980). Microhabitats of a terrestrial salamander. Copeia 1980: 265-268.

Jaeger, R.G., Prosen, E.D. \& Adams, D.C. (2002). Character displacement and aggression in two species of terrestrial salamanders. Copeia 2002: 391-401.

Kniowski, A. \& Reichenbach, N. (2009). The ecology of the Peaks of Otter salamander (Plethodon hubrichti) in sympatry with the Eastern red-backed salamander (Plethodon cinereus). Herpetological Conservation and Biology 4: 285-294.

Kramer, P., Reichenbach, N., Hayslett, M. \& Sattler, P. (1993). Population dynamics and conservation of the Peaks 
of Otter salamander, Plethodon hubrichti. Journal of Herpetology 27: 431-435.

Kroschel, W.A., Sutton, W.B., McClure, C.J.W. \& Pauley, T.K. (2014). Decline of the Cheat Mountain salamander over a 32-year period and the potential influence of competition from a sympatric species. Journal of Herpetology 48:415422.

Marshall, J.L., Camp, C.D. \& Jaeger, J.G. (2004). Potential interference competition between a patchily distributed salamander (Plethodon patraeus) and a sympatric congener (Plethodon glutinosus). Copeia 2004:488-495.

Pague, C.A. \& Mitchell, J.C. (1990). The distribution of the Peaks of Otter salamander (Plethodon hubrichti). Virginia Department of Conservation and Recreation, Division of Natural Heritage Report, Richmond, VA, USA. 16 pp.

Pague, C.A., Hayslett, M. \& Kramer, P. (1992). Field Notes: Plethodon hubrichti (Peaks of Otter salamander): VA: Rockbridge County, Blue Ridge Parkway at Thunder Ridge Overlook. Catesbeiana 12: 9-10.

Pauley, T.K. (1991). Cheat Mountain salamander (Plethodon nettingi) Recovery Plan. US Fish \& Wildlife Service, Northeast Region, Newton Corner, MA. 36 pp.

Pauley, T.K. (2005). Reflections upon amphibian conservation. In Amphibian Declines: the Conservation Status of United States Species, 277-281 pp. Lannoo, M. (Ed.). Berkeley, CA: University of California Press.

Pauley, T.K. (2008). The Appalachian inferno: historical causes for the disjunct distribution of Plethodon nettingi (Cheat Mountain salamander). Northeastern Naturalist 15: 595606.
Petranka, J.W. (1998). Salamanders of the United States and Canada. Washington DC: Smithsonian Institution Press. $592 \mathrm{pp}$.

Reichenbach, N. \& T.R. Brophy. (2017). Natural history of the Peaks of Otter salamander (Plethodon hubrichti) along an elevational gradient. The Herpetological Bulletin 141: 7-15.

Reichenbach, N. \& Sattler, P. (2007). Effects of timbering on Plethodon hubrichti over twelve years. Journal of Herpetology 41: 622-629.

Sattler, P. \& Reichenbach, N. (1998). The effects of timbering on Plethodon hubrichti: short-term effects. Journal of Herpetology 32: 399-404.

Smith, C.K. \& Petranka, J.W. (2000). Monitoring terrestrial salamanders: repeatability and validity of areaconstrained cover object searches. Journal of Herpetology 34: 547-557.

Wicknick, J.A. (1995). Interspecific competition and territoriality between a widespread species of salamander and a species with a limited range. Ph.D. dissertation, University of Southwestern Louisiana, Lafayette, LA. 152 pp.

Wright, R.A.S (1988). A southwestern range extension in Bedford County for the Peaks of Otter Salamander. Catesbeiana 8: 27-28.

Accepted: 31 October 2019 